CLINICAL STUDY

\title{
Changes in tumor necrosis factor- $\alpha$ system and insulin sensitivity during an exercise training program in obese women with normal and impaired glucose tolerance
}

\author{
Marek Strączkowski, Irina Kowalska, Stella Dzienis-Strączkowska, Agnieszka Stępień, Elżbieta Skibińska ${ }^{1}$, \\ Małgorzata Szelachowska and Ida Kinalska \\ Department of Endocrinology and ${ }^{1}$ Department of Cardiology, Medical Academy, Bialystok, Poland \\ (Correspondence should be addressed to Marek Straczkowski, Department of Endocrinology, Medical Academy, M.C. Skłodowskiej 24a, \\ 15-276 Białystok, Poland; Email: mstraczkowski@poczta.onet.pl)
}

\begin{abstract}
Objective: Tumor necrosis factor- $\alpha(\mathrm{TNF} \alpha)$ plays an important role in the pathogenesis of insulin resistance and type 2 diabetes. Plasma levels of the soluble (s) fractions of TNF $\alpha$ receptors, especially sTNFR2, are good indicators of TNF $\alpha$ system activation in obesity. The aim of the present study was to assess the effect of exercise training on the TNF $\alpha$ system and to evaluate the relationship with changes in insulin sensitivity.

Design and methods: Sixteen obese women (body mass index (BMI) $>27.8 \mathrm{~kg} / \mathrm{m}^{2}$ ), 8 with normal (NGT) and 8 with impaired glucose tolerance (IGT), participated in an exercise training program which lasted for 12 weeks and included exercise performed on a bicycle ergometer at an individual intensity of $70 \%$ maximal heart rate, for $30 \mathrm{~min}$, 5 days a week. Anthropometrical measurements and blood biochemical analyses were performed, and plasma TNF $\alpha$, sTNFR 1 and STNFR 2 levels were assessed. Insulin sensitivity was evaluated using the hyperinsulinemic euglycemic clamp technique (insulin infusion: $50 \mathrm{mU} \times \mathrm{kg}^{-1} \times \mathrm{h}^{-1}$ ).

Results: At baseline, despite similar anthropometrical parameters, IGT subjects were markedly more insulin resistant and had higher TNF $\alpha$ and sTNFR2 concentrations. Exercise training increased insulin sensitivity and decreased TNF $\alpha$ and sTNFR2 levels, while sTNFR1 remained unchanged. The decrease in STNFR2 was significantly related to the increase in insulin sensitivity; that relationship remained significant after adjustment for the concurrent changes in BMI, waist circumference, percentage of body fat, plasma glucose, insulin and free fatty acids.

Conclusions: Regular physical exercise decreases TNF $\alpha$ system activity and that decrease may be responsible for the concurrent increase in insulin sensitivity.
\end{abstract}

European Journal of Endocrinology 145 273-280

\section{Introduction}

Tumor necrosis factor- $\alpha(\mathrm{TNF} \alpha)$ is a cytokine which plays a role in the regulation of tissue glucose and lipid metabolism (1). It is expressed in human adipose tissue $(2,3)$ and muscle $(4)$ and is present in higher levels in obese and type 2 diabetic subjects $(2-4)$. It acts probably via autocrine-paracrine mechanisms limiting the amount of body fat (function of 'adipostat'), and inducing insulin resistance. Therefore, TNF $\alpha$ may be an important link between obesity and type 2 diabetes mellitus (1). There are two TNF $\alpha$ cell surface receptors described in humans - TNFR1 (p60), responsible for differentiation and apoptosis, and TNFR2 (p80), which mediates metabolic actions of $\mathrm{TNF} \alpha$ (5). Both receptors are present in all types of human cells and also in plasma in soluble forms (sTNFR1 and sTNFR2) originated from the cell-surface receptors (6). Soluble TNFRs may serve as a reservoir of TNF $\alpha$ by stabilizing its bioactivity (7). It was found that the activation of TNF $\alpha$ leads to overexpression of TNFR2 in adipose tissue and to increased levels of its soluble form in human obesity (6). sTNFR2 levels correlate with body mass index (BMI), fasting insulin (6) and with insulin resistance (8), while there is no such correlation for sTNFR1. These data suggest that TNFR2 plays a role in human obesity by modulating the actions of TNF $\alpha$ and inducing insulin resistance $(6,8)$. Plasma TNF $\alpha$ values are usually low and do not give precise information about its action in obesity, while sTNFR2 is a much more stable protein. Therefore, it is proposed that sTNFR2 might serve as the best predictor of TNF $\alpha$ system activation and as a diagnostic marker for obese individuals with TNF-related insulin resistance (6). 
A sedentary lifestyle contributes to the increased risk of developing type 2 diabetes (9). It is generally accepted that prolonged physical exercise increases insulin sensitivity and might be useful in the prevention of type 2 diabetes (9-11). Great interest is focused on metabolic actions of physical exercise in obesity and insulin resistance. However, there is only limited information about the impact of physical exercise on the TNF $\alpha$ system and whether this impact is related to a degree of glucose tolerance. It is also unclear whether the changes in the $\mathrm{TNF} \alpha$ system might be responsible for the improvement of insulin sensitivity after exercise training.

In the present study, we examine the influence of physical exercise on the TNF $\alpha$ system in obese women with normal or impaired glucose tolerance. We also evaluate the effect of the TNF $\alpha$ system on concurrent changes in insulin sensitivity during an exercise training program.

\section{Subjects and methods}

\section{Study population}

Sixteen sedentary obese women were recruited for this study. All the subjects were pre- or perimenopausal and were not on hormone replacement therapy. All the measurements were taken during the luteal phase because sTNFRs may show variation during the menstrual cycle (12). Subjects underwent an oral glucose tolerance test (OGTT) and on that basis were divided into two groups: one with normal glucose tolerance (NGT, $n=8$ ) and the other with impaired glucose tolerance (IGT, $n=8$ ), according to the World Health Organization criteria. The inclusion criteria were: age between 30 and 50 years, BMI $>27.8 \mathrm{~kg} / \mathrm{m}^{2}$, stable weight and stable hypocaloric diet (according to questionnaire) during the last 4 months, and a sedentary lifestyle. Subjects were excluded from the study if they had diagnosed diabetes, hypertension resistant to pharmacological treatment, ischemic heart disease, peripheral vascular disease, musculoskeletal system disease, infections, other serious medical problems and if they were smoking cigarettes or taking medications known to affect carbohydrate or lipid metabolism. Before the beginning of the program, subjects were examined by a physician and a 12-lead electrocardiogram exercise test was performed. Additionally, 8 healthy, lean $\left(\mathrm{BMI}<25 \mathrm{~kg} / \mathrm{m}^{2}\right)$, age-matched women with normal glucose tolerance were examined at baseline and served as a control group. The study was approved by the Ethics Committee of the Medical Academy, Białystok, and all the subjects gave written informed consent before participating in the study.

\section{Training protocol}

The exercise training program lasted 12 weeks and included exercise performed at the hospital on a bicycle ergometer at an individual intensity of $70 \%$ maximal heart rate. Subjects exercised for $30 \mathrm{~min}, 5$ days a week. Thus an approximate total energy expenditure of $1100 \mathrm{kcal} /$ week was reached. All the training sessions were supervised by a physician, and heart rate and blood pressure were monitored during exercise. A minimum $90 \%$ compliance to the training program was the criterion for inclusion in the data analysis, that criterion was fulfilled by all 16 subjects. Additionally, subjects were encouraged to increase their individual leisure time activity, for instance by walking or swimming. All the additional activities were recorded every 2 weeks in a specially prepared questionnaire. Individual 3-day diet records were also obtained every 2 weeks from all the subjects.

\section{Measurements}

All the measurements were obtained at baseline and after completing a 12-week exercise training protocol. Laboratory analyses were performed at $0800 \mathrm{~h}$ after a 12 -h overnight fast. Analyses were taken at least $48 \mathrm{~h}$ after the last bout of exercise. In the control group measurements were taken only at baseline.

\section{Anthropometry}

The BMI was calculated as body weight $\times$ height $^{-2}$ and expressed in $\mathrm{kg} / \mathrm{m}^{2}$. The waist circumference was measured at the smallest circumference between the rib cage and the iliac crest, with the subject in the standing position. Percentage body fat was estimated by bioelectric impedance analysis using the Tanita TBF-511 Body Fat Analyzer (Tanita Corp., Tokyo, Japan). On that basis fat mass (FM) and fat-free mass (FFM) were calculated.

\section{Insulin sensitivity}

Insulin sensitivity was evaluated by the euglycemic hyperinsulinemic clamp technique as described previously (13). On the morning of the study two venous catheters were inserted into antecubital veins: the first one for the infusion of insulin and glucose and the second one in the contralateral hand for blood sampling - that hand was heated to approximately $60{ }^{\circ} \mathrm{C}$. Insulin (Actrapid HM, Novo Nordisk, Copenhagen, Denmark) was given as a primed-continuous intravenous infusion for $2 \mathrm{~h}$ at $50 \mathrm{mU} \times \mathrm{kg}^{-1} \times \mathrm{h}^{-1}$, resulting in constant hyperinsulinemia of approximately $550 \mathrm{pmol} / \mathrm{l}$. Arterialized blood glucose was obtained every $5 \mathrm{~min}$ and $40 \%$ dextrose $(2.22 \mathrm{~mol} / \mathrm{l})$ infusion was adjusted manually (as modified by Ponchner et al.) (14) to maintain plasma glucose levels at $5.0 \mathrm{mmol} / \mathrm{l}$. The glucose infusion rate approached stable values during the final $40 \mathrm{~min}$ of the study and the rate of whole-body glucose uptake ( $\mathrm{M}$ value) was calculated as the mean glucose infusion rate from 80 to 
Table 1 Clinical and anthropometrical characteristics of the studied groups. Data are expressed as means \pm S.D.

\begin{tabular}{lccc}
\hline & Control $(n=8)$ & NGT $(n=8)$ & IGT $(n=8)$ \\
\hline Age (year) & $38.9 \pm 7.1$ & $36.0 \pm 8.47$ & $38.0 \pm 8.67$ \\
Systolic blood pressure $(\mathrm{mmHg})$ & $125.6 \pm 14.5$ & $133.7 \pm 26.7$ & $144.4 \pm 21.3$ \\
Diastolic blood pressure $(\mathrm{mmHg})$ & $85.6 \pm 10.5$ & $87.5 \pm 11.6$ & $91.2 \pm 11.2$ \\
Body weight $(\mathrm{kg})$ & $61.6 \pm 7.7$ & $86.4 \pm 9.1^{*}$ & $86.2 \pm 10.9 \dagger$ \\
BMl $\left(\mathrm{kg} / \mathrm{m}^{2}\right)$ & $22.63 \pm 1.85$ & $31.17 \pm 4.42^{*}$ & $32.75 \pm 2.21 \dagger$ \\
Waist $(\mathrm{cm})$ & $75.0 \pm 6.46$ & $91.56 \pm 7.04^{\star}$ & $97.62 \pm 4.00 \dagger$ \\
$\%$ Body fat & $18.87 \pm 8.07$ & $33.25 \pm 6.29^{*}$ & $39.31 \pm 8.65 \dagger$ \\
FFM (kg) & $49.61 \pm 3.17$ & $57.38 \pm 7.43^{\star}$ & $52.27 \pm 8.52$ \\
FM (kg) & $12.09 \pm 6.38$ & $28.89 \pm 7.34^{*}$ & $34.41 \pm 10.36 \dagger$ \\
\hline
\end{tabular}

${ }^{\star} P<0.05$ NGT vs control group; $† P<0.05$ IGT vs control group.

$120 \mathrm{~min}$, corrected for glucose space and normalized per kilogram of fat-free mass $\left(\mathrm{M}_{\mathrm{ffm}}\right)$. Plasma insulin and free fatty acids (FFA) were also measured during the clamp.

\section{Other blood analyses}

Fasting blood samples were also taken from the antecubital vein before the beginning of the clamp for the determination of glycated hemoglobin $(\mathrm{HbAlc}$ ), plasma lipids, TNF $\alpha$, sTNFR1 and sTNFR2. For the determination of plasma TNF system samples were frozen at $-70{ }^{\circ} \mathrm{C}$.

\section{Analytical procedures}

Plasma glucose was measured enzymatically using a commercially available kit (Cormay Glucose, Warsaw, Poland). Plasma insulin were measured in duplicate with the Medgenix EASIA test (BioSource Europe, Nivelles, Belgium). The minimum detectable concentration was $1.05 \mathrm{pg} / \mathrm{l}$ and the intra-assay and interassay coefficients of variation were below 5.5 and $10 \%$ respectively. In this method human and animal proinsulins present no cross-reaction. $\mathrm{HbAlc}$ was measured by the high-performance liquid chromatography method (Bio-Rad, Munchen, Germany). Plasma cholesterol and triglycerides (TG) were assessed by enzymatic methods (Cormay). Plasma FFA were measured by a colorimetric method (15).

Plasma TNF $\alpha$ concentrations were measured by the immunoassay kit from BioSource International (Camarillo, CA, USA) with a minimum detectable dose of $1.7 \mathrm{pg} / \mathrm{ml}$ and with intra-assay and interassay coefficients of variation below 5.2 and $8.5 \%$ respectively. Plasma sTNFR1 and sTNFR2 were determined with the EASIA kits (BioSource Europe). The minimum detectable concentration was estimated to be 0.05 $\mathrm{ng} / \mathrm{ml}$ for sTNFR 1 and $0.1 \mathrm{ng} / \mathrm{ml}$ for sTNFR 2 . The intra-assay and interassay coefficients of variation for both receptors were below 6.5 and 9\% respectively. sTNFR1 EASIA does not cross react with sTNFR2, and $\mathrm{TNF} \alpha$ does not interfere with the assay.

\section{Statistical analysis}

All the data are presented as means \pm S.D. The statistics were performed using the STATISTICA 5.0 program (StatSoft, Krakow, Poland). Comparison between control, NGT and IGT groups was carried out using the Mann-Whitney $U$ test. The statistical significance between variables before and after the training program was analyzed by the Wilcoxon rank sum test. Simple, multiple and stepwise regression analyses were performed to evaluate the relationships between

Table 2 Biochemical parameters of the studied groups. Data are expressed as means \pm S.D.

\begin{tabular}{lccc}
\hline & Control $(n=8)$ & NGT $(n=8)$ & IGT $(n=8)$ \\
\hline Fasting plasma glucose $(\mathrm{mmol} / \mathrm{l})$ & $4.86 \pm 0.47$ & $5.37 \pm 0.48$ & $6.02 \pm 0.56 \dagger, \ddagger$ \\
Fasting plasma insulin $(\mathrm{pmol} / \mathrm{l})$ & $38.72 \pm 10.0$ & $72.65 \pm 19.04^{\star}$ & $121.61 \pm 47.31 \dagger, \ddagger$ \\
Plasma FFA (mmol/l) & $337.5 \pm 96.0$ & $421.2 \pm 62.7$ & $780.0 \pm 194.3 \dagger, \ddagger$ \\
HbA1c $(\%)$ & $5.07 \pm 0.36$ & $5.80 \pm 0.30^{\star}$ & $6.44 \pm 0.54 \dagger, \ddagger$ \\
Plasma cholesterol $(\mathrm{mmol} / \mathrm{l})$ & $4.33 \pm 1.02$ & $5.75 \pm 0.99^{\star}$ & $6.05 \pm 1.59 \dagger$ \\
Plasma TG $(\mathrm{mmol} / \mathrm{l})$ & $0.82 \pm 0.44$ & $1.27 \pm 0.60$ & $2.29 \pm 1.31 \dagger$ \\
$\mathrm{M}_{\mathrm{ffm}}\left(\mu \mathrm{mol} \times \mathrm{kg}^{-1} \times \mathrm{min}^{-1}\right)$ & $50.54 \pm 6.19$ & $40.40 \pm 7.41^{\star}$ & $21.02 \pm 13.84 \dagger, \ddagger$ \\
TNF $\alpha(\mathrm{pg} / \mathrm{ml})$ & $3.27 \pm 0.39$ & $3.88 \pm 0.49^{\star}$ & $6.59 \pm 2.31 \dagger, \ddagger$ \\
sTNFR1 $(\mathrm{ng} / \mathrm{ml})$ & $1.84 \pm 0.15$ & $2.05 \pm 0.32$ & $2.10 \pm 0.54$ \\
sTNFR2 $(\mathrm{ng} / \mathrm{ml})$ & $3.47 \pm 0.42$ & $4.04 \pm 0.61^{\star}$ & $5.27 \pm 0.41 \dagger, \ddagger$ \\
\hline
\end{tabular}

${ }^{*} P<0.05$ NGT vs control group; $\dagger P<0.05$ IGT vs control group; $¥ P<0.05$ IGT vs NGT group. 
before training
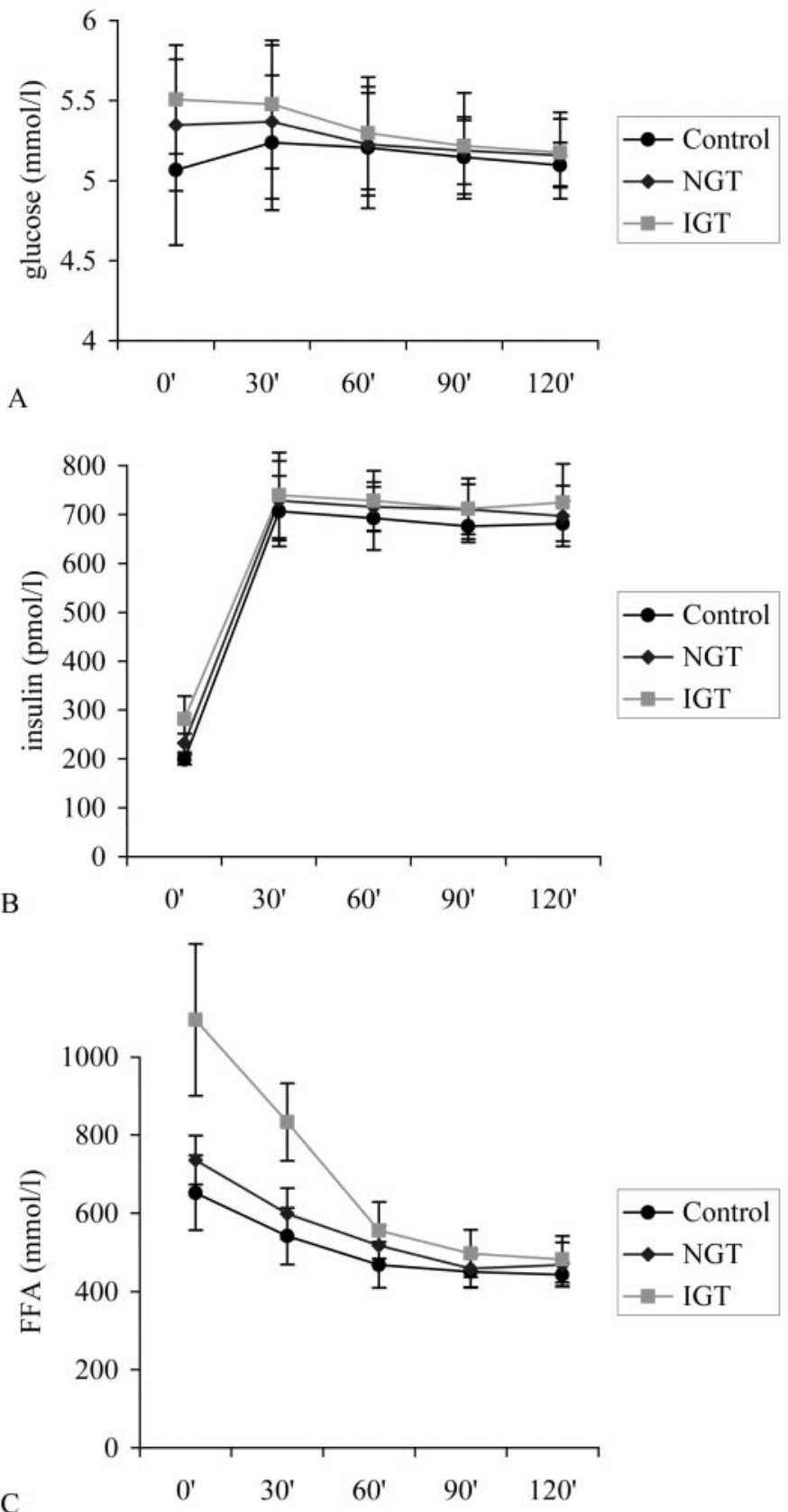
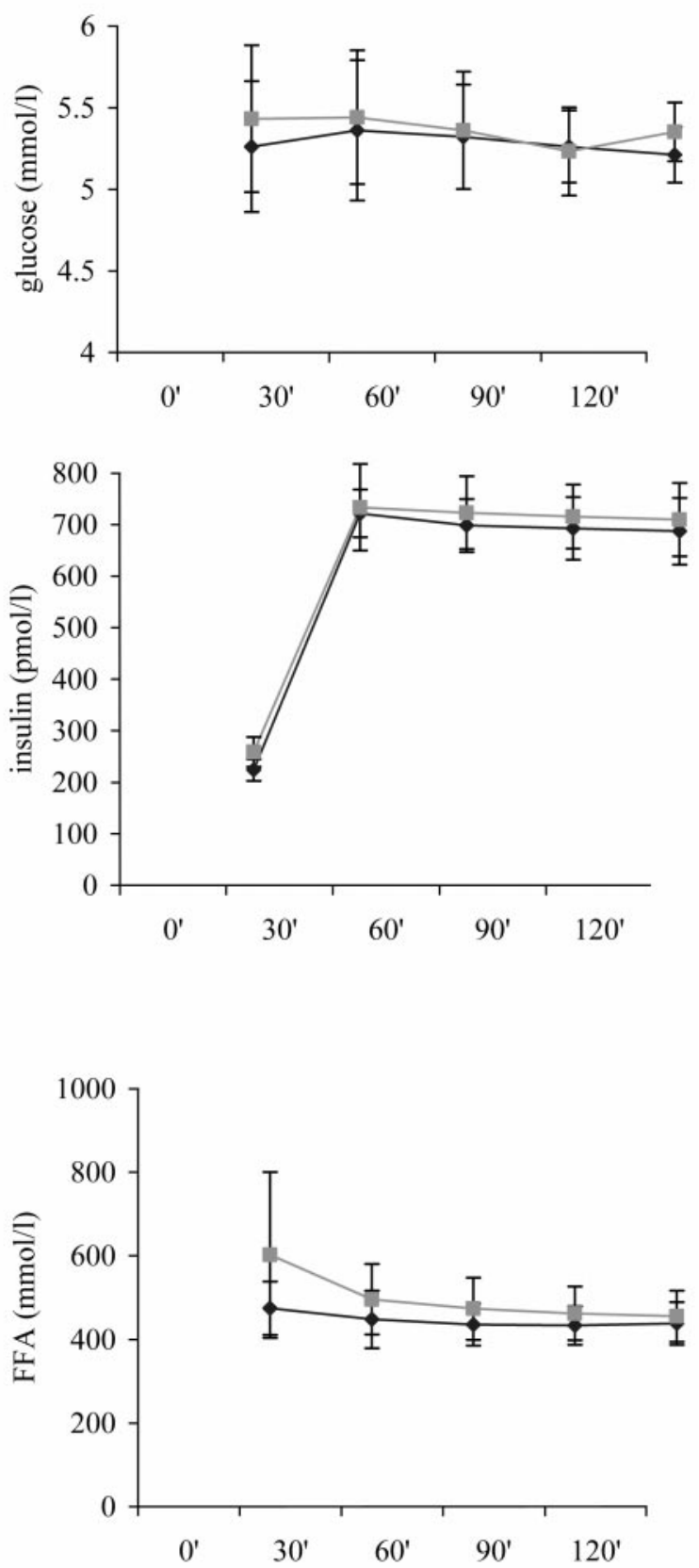

Figure 1 Plasma glucose $(A)$, insulin $(B)$ and FFA $(C)$ during euglycemic hyperinsulinemic clamp before and after training.

variables. The statistical significance was accepted at a $P$ value of less than 0.05 .

\section{Results}

The anthropometrical and biochemical characteristics of the studied groups are presented in Tables 1 and 2 . There was no significant difference in anthropometrical measurements between the NGT and IGT groups. As expected, IGT subjects demonstrated markedly higher fasting plasma glucose, insulin, FFA, and $\mathrm{HbAlc}$ when compared with the NGT and control group $(P<0.05$ in all cases). Also, IGT subjects were significantly more insulin resistant than NGT subjects and controls $(P<0.005$ in both cases). Obese NGT women had markedly higher plasma insulin and $\mathrm{HbAlc}$ and lower $\mathrm{M}_{\mathrm{ffm}}$ in comparison with the control group (all $P<0.05)$, while the differences in plasma glucose 


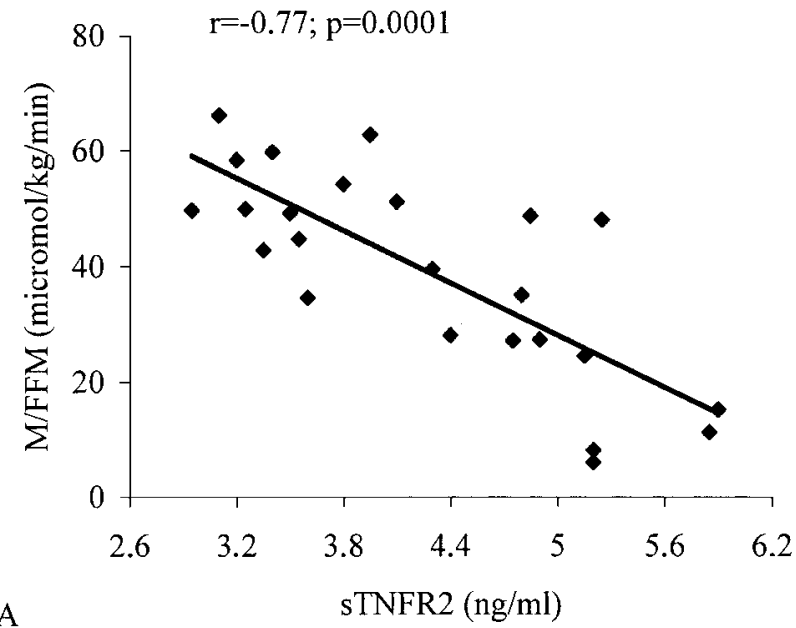

A

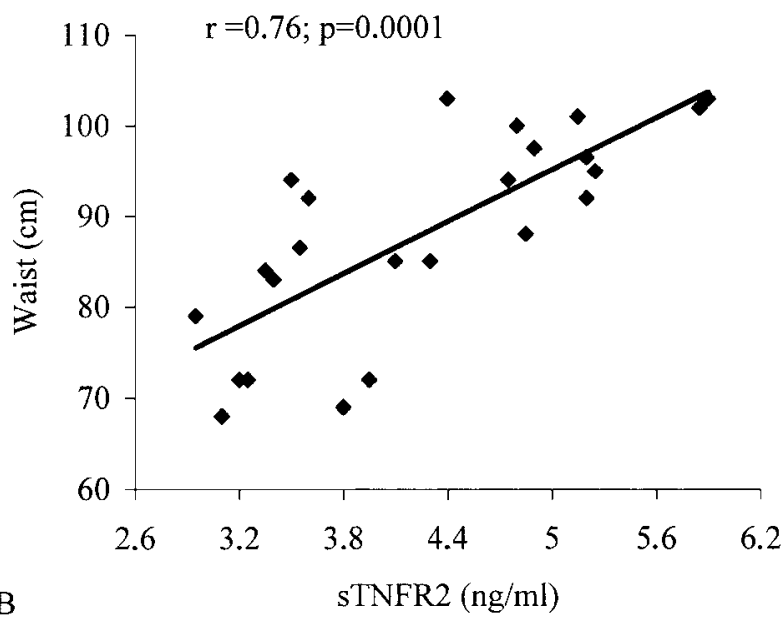

Figure 2 Correlation between baseline sTNFR2 and $M_{\mathrm{ffm}}$ value (A) and waist circumference (B).

and FFA were approaching the level of significance (glucose: $P=0.051$; FFA: $P=0.065$ ). No significant differences were observed in plasma glucose, insulin and FFA during steady-state clamp conditions between the studied groups (Fig. 1).

Plasma levels of TNF $\alpha$ and sTNFR 2 were significantly higher in both groups of the obese subjects compared with control (IGT vs control: both $P<0.001$; NGT vs control: both $P<0.05)$ and in the IGT compared with the NGT group (both $P<0.005$ ). No differences in plasma sTNFR1 levels were observed between the studied groups (Table 2).

Basal sTNFR2 levels correlated positively with BMI, waist circumference, $\mathrm{HbA1c}$, plasma insulin and FFA and negatively with $\mathrm{M}_{\mathrm{ffm}}$ (Fig. 2). These correlations remained significant when the lean women were excluded from the analysis (Table 3). There were no significant correlations between sTNFR1 and the above parameters. TNF $\alpha$ correlated with sTNFR2 $(r=0.76$; $P=0.0005)$. The correlations between TNF $\alpha$ and the other variables mentioned above, although significant
Table 3 Correlations between baseline sTNFR2 and anthropometrical and biochemical variables.

\begin{tabular}{lrrrrr}
\hline & $\begin{array}{c}\text { All the subjects } \\
\text { studied }(n=24)\end{array}$ & \multicolumn{2}{c}{$\begin{array}{c}\text { Obese NGT and IGT } \\
\text { subjects }(n=16)\end{array}$} \\
\cline { 2 - 3 } \cline { 5 - 6 } \cline { 5 - 6 } & $r$ & $P$-value & & $r$ & $P$-value \\
\hline BMI & 0.71 & 0.0005 & & 0.51 & 0.046 \\
Waist & 0.76 & 0.0001 & & 0.65 & 0.007 \\
\% Body fat & 0.63 & 0.001 & & 0.44 & 0.09 \\
FM & 0.64 & 0.001 & & 0.39 & 0.14 \\
FFM & 0.14 & 0.54 & & 0.21 & 0.44 \\
Plasma glucose & 0.59 & 0.002 & & 0.45 & 0.08 \\
Plasma insulin & 0.71 & 0.0005 & & 0.57 & 0.02 \\
Plasma FFA & 0.68 & 0.0008 & & 0.61 & 0.012 \\
HbA1c & 0.70 & 0.0007 & & 0.55 & 0.027 \\
M & -0.77 & 0.0001 & & -0.66 & 0.006 \\
Plasma cholesterol & 0.35 & 0.09 & & -0.04 & 0.88 \\
Plasma TG & 0.52 & 0.009 & & 0.35 & 0.18 \\
\hline
\end{tabular}

in most cases, were weaker than those for sTNFR2. Therefore, in studying relationships between variables we chose sTNFR 2 as the best predictor of TNF $\alpha$ system activity.

Exercise training resulted in a significant decrease in BMI, waist circumference, percentage body fat, HbA1c and FFA in both groups of the obese subjects (all $P<0.05$ ) (Table 4). A marked increase in $\mathrm{M}_{\mathrm{ffm}}$ was also observed ( $P<0.02$ in both groups). The observed decrease in most of the parameters was similar in NGT and IGT groups, while alterations in plasma FFA and the $\mathrm{M}_{\mathrm{ffm}}$ value were markedly more pronounced in the IGT group $\left(\Delta \mathrm{FFA}\right.$ and $\Delta \mathrm{M}_{\mathrm{ffm}}$ : IGT vs NGT, $\left.P<0.02\right)$.

We demonstrated a significant impact of exercise training on the TNF $\alpha$ system: after completing the study plasma TNF $\alpha$ and sTNFR2 decreased significantly in both groups (all $P<0.02$ ), while sTNFR1 levels remained unchanged (Table 5). The observed decrease in sTNFR2 was markedly greater in the IGT group $(P<0.05)$, while for the changes in TNF $\alpha$ there was no such difference.

The fall in sTNFR 2 was the greatest in the subjects with the highest baseline sTNFR2 $(r=0.52 ; P<0.05)$ and the lowest $\mathrm{M}_{\mathrm{ffm}}(r=-0.62 ; P<0.01)$. During training, sTNFR2 levels changed concurrently with the decrease in waist circumference $(r=0.51 ; P<0.05)$, FFA $(r=0.59 ; P<0.02)$ and with the increase in insulin sensitivity $(r=-0.70 ; P<0.005)$ (Fig. 3).

During multiple regression analysis with $\Delta \mathrm{M}_{\mathrm{ffm}}$ as the dependent variable, we found that $\triangle$ sTNFR2 was determining the $\mathrm{M}_{\mathrm{ffm}}$ changes independently of changes in BMI, waist circumference, percentage body fat, and plasma glucose, insulin and FFA (beta value $=-0.53 ; P<0.05)$. In a stepwise regression analysis only the changes in waist circumference and sTNFR2 were independent factors influencing the changes in insulin sensitivity $\left(\mathrm{R}^{2}=0.77 ; P<0.001\right)$ with changes in BMI, percentage body fat, plasma glucose, insulin and FFA not entering the regression model. 
Table 4 Effects of exercise training on anthropometrical and metabolic parameters in the NGT and IGT groups. Data are expressed as means \pm S.D.

\begin{tabular}{|c|c|c|c|c|}
\hline & $\begin{array}{c}\text { NGT before } \\
\text { training }(n=8)\end{array}$ & $\begin{array}{c}\text { NGT after } \\
\text { training }(n=8)\end{array}$ & $\begin{array}{c}\text { IGT before } \\
\text { training }(n=8)\end{array}$ & $\begin{array}{c}\text { IGT after } \\
\text { training }(n=8)\end{array}$ \\
\hline Body weight $(\mathrm{kg})$ & $86.4 \pm 9.1$ & $84.4 \pm 8.8^{*}$ & $86.2 \pm 10.9$ & $84.5 \pm 10.7^{*}$ \\
\hline BMI $\left(\mathrm{kg} / \mathrm{m}^{2}\right)$ & $31.17 \pm 4.42$ & $30.43 \pm 2.06^{*}$ & $32.75 \pm 2.21$ & $31.92 \pm 1.85^{*}$ \\
\hline Waist $(\mathrm{cm})$ & $91.56 \pm 7.04$ & $89.81 \pm 7.18^{\star}$ & $97.62 \pm 4.00$ & $94.75 \pm 3.94^{*}$ \\
\hline$\%$ Body fat & $33.25 \pm 6.29$ & $31.94 \pm 5.96^{*}$ & $39.31 \pm 8.65$ & $36.81 \pm 8.45^{\star}$ \\
\hline FFM $(\mathrm{kg})$ & $57.38 \pm 7.43$ & $57.34 \pm 7.30$ & $52.27 \pm 8.52$ & $53.24 \pm 9.23$ \\
\hline $\mathrm{FM}(\mathrm{kg})$ & $28.89 \pm 7.34$ & $27.05 \pm 6.51^{*}$ & $34.41 \pm 10.36$ & $31.26 \pm 8.83^{*}$ \\
\hline Plasma glucose $(\mathrm{mmol} / \mathrm{l})$ & $5.37 \pm 0.48$ & $5.31 \pm 0.55$ & $6.02 \pm 0.56$ & $5.85 \pm 1.00$ \\
\hline Plasma insulin (pmol/l) & $72.65 \pm 19.04$ & $65.80 \pm 21.04$ & $121.61 \pm 47.31$ & $100.53 \pm 29.01^{*}$ \\
\hline Plasma FFA (mmol/l) & $421.2 \pm 62.7$ & $168.75 \pm 64.02^{\star}$ & $780.0 \pm 194.3$ & $296.25 \pm 198.63^{\star}$ \\
\hline $\mathrm{HbA1c}(\%)$ & $5.80 \pm 0.30$ & $4.91 \pm 0.48^{\star}$ & $6.44 \pm 0.54$ & $5.41 \pm 0.54^{*}$ \\
\hline $\mathrm{M}_{\mathrm{ffm}}\left(\mu \mathrm{mol} \times \mathrm{kg}^{-1} \times \mathrm{min}^{-1}\right)$ & $40.40 \pm 7.41$ & $44.87 \pm 6.92^{*}$ & $21.02 \pm 13.84$ & $32.43 \pm 16.82^{*}$ \\
\hline
\end{tabular}

${ }^{*} P<0.05$ for the differences between before and after training values.

According to the questionnaire, in almost all the patients additional physical activity consisted of $30 \mathrm{~min}$ walking and/or biking daily. Diet records collected during the study did not differ significantly from the questionnaire which was filled in at the beginning of the study. The approximate daily intake was 1200-1400 kcal.

\section{Discussion}

In the present study we demonstrated a significant decrease in TNF $\alpha$ and sTNFR 2 after exercise training, observed in both NGT and IGT groups. It remains unclear what is the source of the increased circulating $\mathrm{TNF} \alpha$ in obese individuals; however, adipose tissue is the probable candidate because of the overexpression of the TNF $\alpha$ gene. TNF $\alpha$ levels are also dependent on type of obesity (16). Previous studies reported a marked decrease of TNF $\alpha$ expression in adipose tissue $(2,3)$ and a decrease in circulating $\operatorname{TNF} \alpha(17,18)$ after weight loss. We also observed a slight decrease in body weight, waist circumference and fat mass, which is attributed mainly to the increase in physical activity, as the hypocaloric diet was unchanged in comparison with the pre-treatment period. However, body weight decreased by $2.19 \%$ and fat mass by $7.90 \%$, and it was accompanied by a $19.57 \%$ loss of TNF $\alpha$ and a $19.85 \%$ loss of sTNFR 2 . Therefore, we suggest that increased physical activity has an independent effect regulating the TNF system, which cannot be attributed only to changes in body fat. It was reported that TNF $\alpha$ is also overexpressed in skeletal muscle of insulin resistant and diabetic subjects (4). Fernandez-Real et al. reported that sTNFR 2 correlated with fat-free mass and suggested that circulating sTNFR 2 is produced not only by the adipocytes but also by the muscle (8). We were unable to detect such a relationship at baseline, but this is probably due to a rather narrow range of FFM values in our subjects and to the selection of the study groups (weight-matched insulin-resistant IGT subjects had slightly higher percentage of body fat and slightly lower FFM). However, in the present study FFM did not change significantly after training. Although our study does not answer that question, it is possible that muscle contraction may directly regulate local $\mathrm{TNF} \alpha$ expression and muscle activity may be more important than muscle mass. Increased sTNFR 2 concentrations were found in patients with myotonic dystrophy (19). The authors speculated that disorders of the muscle cell membrane could lead both to insulin resistance and to sTNFR2 leakage. It is also possible that muscle inactivity may modulate $\mathrm{TNF} \alpha$ system action in that group of patients.

In a very recently published paper the influence of moderate physical exercise on plasma TNF $\alpha$ was also examined (20) and the decrease in TNF $\alpha$ and both sTNFRs in healthy women was observed. Changes in sTNFRs were not related to changes in anthropometrical measurements (20). We did not find any effect of exercise training on sTNFR1. The discrepancy

Table 5 TNF $\alpha$ system before and after training in the NGT and IGT groups. Data are expressed as means \pm S.D.

\begin{tabular}{lcccc}
\hline & $\begin{array}{c}\text { NGT before } \\
\text { training }(n=8)\end{array}$ & $\begin{array}{c}\text { NGT after } \\
\text { training }(n=8)\end{array}$ & $\begin{array}{c}\text { IGT before } \\
\text { training }(n=8)\end{array}$ & $\begin{array}{c}\text { IGT after } \\
\text { training }(n=8)\end{array}$ \\
\hline TNF $\alpha(\mathrm{pg} / \mathrm{ml})$ & $3.88 \pm 0.49$ & $3.27 \pm 0.54^{*}$ & $6.59 \pm 2.31$ & $5.15 \pm 1.19^{\star}$ \\
sTNFR1 $(\mathrm{ng} / \mathrm{ml})$ & $2.05 \pm 0.32$ & $2.02 \pm 0.35$ & $2.10 \pm 0.54$ & $2.07 \pm 0.56$ \\
sTNFR2 $(\mathrm{ng} / \mathrm{ml})$ & $4.04 \pm 0.61$ & $3.34 \pm 0.58^{*}$ & $5.27 \pm 0.41$ & $4.12 \pm 0.59^{\star}$ \\
\hline
\end{tabular}

${ }^{*} P<0.05$ for the differences between before and after training values. 


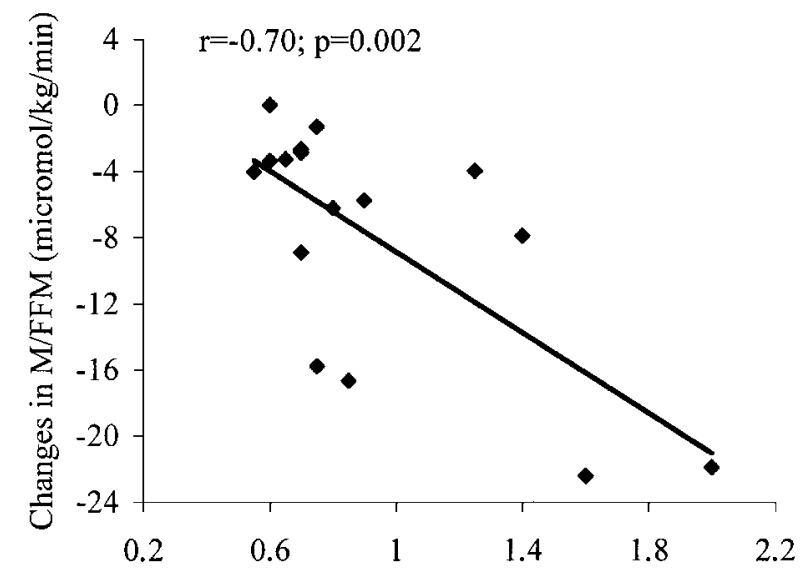

A

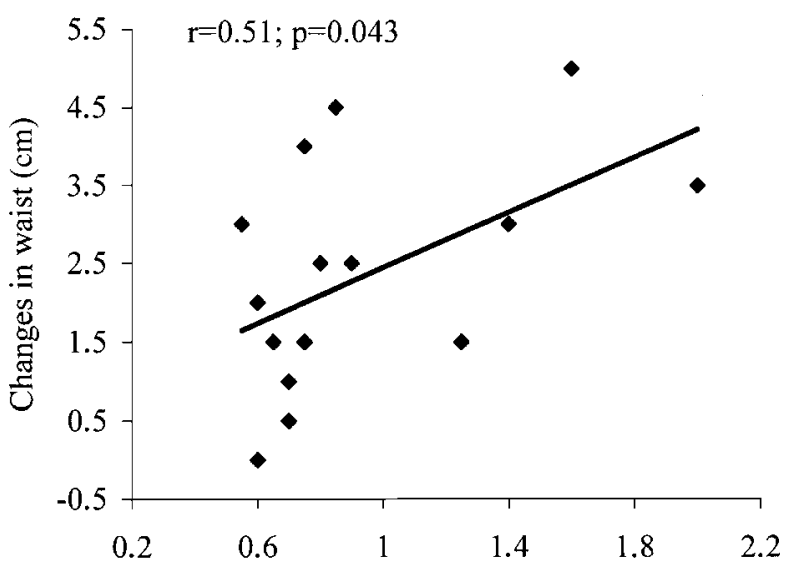

B

Changes in sTNFR2 $(\mathrm{ng} / \mathrm{ml})$

Figure 3 Correlation between changes in sTNFR2 and changes in $\mathrm{M}_{\mathrm{ffm}}$ value (A) and waist circumference (B).

between the two studies cannot be explained by the inclusion of the IGT group in our study, as the IGT group had similar anthropometrical parameters and sTNFR1 levels as the NGT group. However, in the present study baseline sTNFR1 levels in obese subjects were not increased compared with controls. This is consistent with the previously reported results $(6,8)$. We suppose that the two sTNFRs are regulated in different ways because of their different functions (5). In contrast to the above data, increased sTNFR1 levels in obesity were also observed $(20,21)$ and this discrepancy has not been explained so far. The difference may come from the selection of study subjects - men show higher levels of sTNFRs than women (8), and in women there could also be a variation due to a menstrual cycle (12). In the cited paper, the decrease in TNF $\alpha$ was related to the decrease in FFM (20); however we think that this may not be applicable to all situations as unchanged and increased values of FFM after endurance training were also reported (22).
Another important finding of our study is that decreases in TNF $\alpha$ and sTNFR2 are related to the increase in insulin sensitivity after exercise training. The mechanisms by which physical activity enhances insulin action are not fully understood. It is well-known that skeletal muscle is the major site of insulin action and accounts for about 90\% of insulin-stimulated glucose uptake during an insulin clamp (23). Increased FFA supply from visceral fat to muscle may suppress glucose utilization through a glucose-fatty acids cycle (24). Therefore, one of the proposed mechanisms explaining the relationship between changes in sTNFR2 and insulin sensitivity may be decreased lipolysis and FFA delivery, as alterations in sTNFR2 paralleled those of waist circumference and FFA levels. However, the relationship between changes in STNFR2 and insulin sensitivity remained significant after adjustment for the concurrent changes in waist circumference, FFA and other measurements of adiposity. Changes of waist circumference and sTNFR2 were both independent correlates of the increase in $\mathrm{M}_{\mathrm{ffm}}$ suggesting different mechanisms of action. Saghizadeh et al. found a significant inverse relationship between muscle TNF and maximal glucose disposal rate (4). They speculated that disordered TNF regulation in muscle may be an important part of insulin resistance. Although TNF acts locally in muscle, circulating sTNFR2 may reflect local action of the cytokine (6). We present data, the first to our knowledge, that changes in the TNF system are related to the improvement in insulin sensitivity during prolonged physical activity. Although our results do not reveal any cause-effect relationship, we can hypothesize that muscle contraction may decrease local TNF $\alpha$ and sTNFR2 expression and this may lead to the increased insulin sensitivity. There are also other changes resulting in enhanced insulin action following training, such as increased amount of the glucose transporter GLUT4 (25-27), increased capillarization of the muscle tissue (28) and enhanced insulin signal transduction, for example at the level of phosphatidylinositol 3-kinase activity (29). Therefore, a decrease in TNF $\alpha$ expression is only one among many other proposed mechanisms.

It is generally accepted that individuals who are at highest risk of developing type 2 diabetes, i.e. with the greatest visceral obesity, impaired glucose tolerance and insulin resistance, benefit most from performing regular physical activity (9). In the present study, increase in insulin sensitivity was greater in IGT subjects despite similar changes in anthropometrical measurements of obesity, while the decrease in sTNFR 2 was markedly larger in this group. Our data show that regulation of the TNF $\alpha$ system by physical activity is dependent on the glucose tolerance status and baseline sTNFR2 levels, and this may contribute to differences in metabolic response to exercise training in different groups of subjects. The present study does not explain the reason for such differences. 
We conclude that regular physical exercise decreases TNF $\alpha$ system activity and that this decrease may be responsible for the concurrent increase in insulin sensitivity. Although such a decrease is present in both NGT and IGT women, the degree of change in the TNF $\alpha$ system is dependent on glucose tolerance status.

\section{References}

1 Hotamisligil GS \& Spiegelman BM. Tumor necrosis factor $\alpha$ : a key component of the obesity-diabetes link. Diabetes $1994 \mathbf{4 3}$ $1271-1278$.

2 Kern PA, Saghizadeh M, Ong JM, Bosch RJ, Deem R \& Simsolo RB. The expression of tumor necrosis factor in human adipose tissue. Regulation by obesity, weight loss, and relationship to lipoprotein lipase. Journal of Clinical Investigation $1995952111-2119$.

3 Hotamisligil GS, Arner P, Caro JF, Atkinson RL \& Spiegelman BM. Increased adipose tissue expression of tumor necrosis factor- $\alpha$ in human obesity and insulin resistance. Journal of Clinical Investigation 199595 2409-2415.

4 Saghizadeh M, Ong JM, Garvey WT, Henry RR \& Kern PA. The expression of TNF $\alpha$ by human muscle. Relationship to insulin resistance. Journal of Clinical Investigation 199697 1111-1116.

5 Bazzoni $\mathrm{F} \&$ Beutler B. The tumor necrosis factor ligand and receptor families. New England Journal of Medicine 1996334 1717-1725.

6 Hotamisligil GS, Arner P, Atkinson RL \& Spiegelman BM. Differential regulation of the p80 tumor necrosis factor receptor in human obesity and insulin resistance. Diabetes $1997 \mathbf{4 6}$ 451-455.

7 Aderka D, Engelmann H, Maor Y, Brakebusch C \& Wallach D. Stabilization of the bioactivity of tumor necrosis factor by its soluble receptors. Journal of Experimental Medicine 1992175 323-329.

8 Fernandez-Real JM, Broch M, Ricart W, Casamitjana R, Gutierrez C, Vendrell J et al. Plasma levels of the soluble fraction of tumor necrosis factor receptor 2 and insulin resistance. Diabetes 199847 1757-1762.

9 Eriksson J, Taimela S \& Koivisto VA. Exercise and the metabolic syndrome. Diabetologia 199740 125-135.

10 Mayer-Davis EJ, D’Agostino R, Karter AJ, Haffner SM, Rewers MJ, Saad $\mathrm{M}$ et al. Intensity and amount of physical activity in relation to insulin sensitivity. JAMA $1998 \mathbf{2 7 9} 669-674$.

11 Helmrich SP, Ragland DR, Leung RW \& Paffenbarger RS. Physical activity and reduced occurrence of non-insulin-dependent diabetes mellitus. New England Journal of Medicine 1991325 147-152.

12 Fernandez-Real JM, Gutierrez C, Vendrell J, Casamitjana R \& Ricart W. Plasma soluble tumor necrosis factor- $\alpha$ receptors circulate in proportion to leptin levels during the menstrual cycle in lean but not in obese women. European Journal of Endocrinology $2000143235-241$.

13 DeFronzo RA, Tobin JD \& Andres R. Glucose clamp technique: a method for quantifying insulin secretion and resistance. American Journal of Physiology 1979237 E214-E223.

14 Ponchner M, Heine RJ, Pernet A, Hanning I, Francis AJ, Cook D et al. A comparison of the artificial pancreas (glucose controlled insulin infusion system) and a manual technique for assessing insulin sensitivity during euglycemic clamping. Diabetologia 1984 26 420-425.
15 Duncombe WS. The colorimetric microdetermination of nonesterified fatty acids in plasma. Clinica Chimica Acta 19649 $122-135$.

16 Tsigos C, Kyrou I, Chala E, Tsapogas P, Stavridis JC, Raptis SA et al. Circulating tumor necrosis factor alpha concentrations are higher in abdominal versus peripheral obesity. Metabolism $1999481332-1335$.

17 Katsuki A, Sumida Y, Murashima S, Murata K, Takarada Y, Ito K et al. Serum levels of tumor necrosis factor- $\alpha$ are increased in obese patients with non-insulin dependent diabetes mellitus. Journal of Clinical Endocrinology and Metabolism $1998 \mathbf{8 3}$ 859-862.

18 Dandona P, Weinstock R, Thusu K, Abdel-Rahman E, Aljada A \& Wadden T. Tumor necrosis factor- $\alpha$ in sera of obese patients: fall with weight loss. Journal of Clinical Endocrinology and Metabolism $1998832907-2910$.

19 Fernandez-Real JM, Molina A, Broch M, Ricart W, Gutierrez C, Casamitjana $\mathrm{R}$ et al. Tumor necrosis factor system is associated with insulin resistance and dyslipidemia in myotonic dystrophy. Diabetes 199948 1108-1112.

20 Tsukui S, Kanda T, Nara M, Nishino M, Kondo T \& Kobayashi I. Moderate-intensity regular exercise decreases serum tumor necrosis factor- $\alpha$ and $\mathrm{HbA1c}$ levels in healthy women. International Journal of Obesity 200024 1207-1211.

21 Hauner H, Bender M, Haastert B \& Hube F. Plasma concentrations of soluble TNF-alpha receptors in obese subjects. International Journal of Obesity 199822 1239-1243.

22 Perusse L, Collier G, Gagnon J, Leon AS, Rao DC, Skinner JS et al. Acute and chronic effects of exercise on leptin levels in humans. Journal of Applied Physiology 199783 5-10.

23 Berrish TS, Hetherington CS, Alberti KGMM \& Walker M. Peripheral and hepatic insulin sensitivity in subjects with impaired glucose tolerance. Diabetologia 199538 699-704.

24 Roden M, Price TB, Perseghin G, Petersen KF, Rothman DL, Cline GW et al. Mechanisms of free fatty acid-induced insulin resistance in humans. Journal of Clinical Investigation $1996 \mathbf{9 7}$ 2859-2865.

25 Dela F, Ploug T, Handberg A, Petersen LN, Larsen JJ, Mikines KJ et al. Physical training increases muscle GLUT4 protein and mRNA in patients with NIDDM. Diabetes $199443862-865$.

26 Lund S, Holman GD, Schmitz O \& Pedersen O. Contraction stimulates translocation of glucose transporter GLUT4 in skeletal muscle through a mechanism distinct from that of insulin. PNAS $1995925817-5821$.

27 Daugaard JR, Nielsen JN, Kristiansen S, Andersen JL, Hargreaves M \& Richter EA. Fiber type-specific expression of GLUT4 in human skeletal muscle: influence of exercise training. Diabetes $2000491092-1095$.

28 Green H, Goreham C, Ouyang J, Ball-Burnett M \& Ranney D. Regulation of fiber size, oxidative potential, and capillarization in human muscle by resistance exercise. American Journal of Physiology 1999276 R591-R596.

29 Houmard JA, Shaw CD, Hickey MS \& Tanner CJ. Effect of shortterm exercise training on insulin-stimulated PI 3-kinase activity in human skeletal muscle. American Journal of Physiology 1999 277 E1055-E1060.

Received 28 December 2000

Accepted 4 May 2001 